\title{
Effects of motivation of the patient on indices of exercise capacity in chronic heart failure
}

\author{
A L Clark, P A Poole-Wilson, A J S Coats
}

Department of Cardiac Medicine, National Heart and Lung Institute, London

A L Clark

P A Poole-Wilson

A J S Coats

Correspondence to: Dr A J S Coats, Department of Cardiac Medicine, National Heart and Lung National Heart and Lung Institute, Dovehouse

Accepted for publication 15 September 1993

\begin{abstract}
Background-Measurement of variables of metabolic gas exchange during exercise is widely used to assess the severity of heart failure. The variables derived however, are potentially dependent on motivation of the patient and duration of exercise.

Methods-The data from exercise tests in 23 patients with exertional breathlessness were analysed to derive the following three common indices of exercise tolerance: anaerobic threshold, extrapolated maximum oxygen consumption, and the ventilation to carbon dioxide production slope. The data were reanalysed with the data points from the first $90 \%$ of subsequent exercise, the first $75 \%$, and finally the data up to the point where a respiratory gas exchange ratio of 1 was reached. Results-The mean (SEM) anaerobic threshold was lower when computed from $90 \%$ of the data points than from $100 \%(13.2(1.0) \mathrm{ml} / \mathrm{kg} / \mathrm{min} v 12.5(1.0), \mathrm{p}$ $<0.001)$ and lower still from 75\% (11.4 (0.7), $p=0.006 v 90 \%)$. Extrapolated maximum oxygen consumption was unchanged when computed from $90 \%$ of the data, but higher when computed from $75 \%(25.4(2 \cdot 1) \mathrm{ml} / \mathrm{kg} / \mathrm{min}$ at $100 \% v$ $28.6(2.1)$ at $75 \%, p<0.001)$. The slope of the ventilation to carbon dioxide production ratio became progressively shallower measured from $90 \%$ and $75 \%$ of eventual exercise: $32.3(1.5)$ from $100 \% v$ $30.0(1.5)$ from $90 \%, p<0.001$; and 28.3 from $75 \%, \mathrm{p}<0.001 v 90 \%$. At a respiratory gas exchange ratio of 1 , extrapolated oxygen consumption was unchanged from the final calculation, anaerobic threshold was lower than at $100 \%$ of exercise $(11.8(0.9), p=0.005)$ and the ventilation to carbon dioxide production slope was shallower $(27.5(1 \cdot 4), \quad p<$ 0.001).

Conclusions-Anaerobic threshold tends to overestimate severity of exercise limitation and extrapolated maximum oxygen consumption and the ventilation to carbon dioxide production slope tend to underestimate severity. Extrapolated maximum oxygen consumption is the most reliable of the three measures, and is independent of effort provided that patients are encouraged to exercise to the point where the respiratory gas exchange ratio exceeds 1 .
\end{abstract}

(Br Heart F 1994;71:162-165)
Exercise testing with expired gas analysis to derive indices of metabolic gas exchange is a widely used technique for assessing the functional capacity of patients with chronic heart failure. Maximum oxygen consumption $\mathrm{VO}_{2}$ max) relates to functional capacity..$^{1-3}$ In practice, oxygen consumption $\left(\mathrm{Vo}_{2}\right)$ reached is measured rather than a theoretical $\mathrm{Vo}_{2} \max$ defined as a plateau of oxygen consumption with increasing external work. Patients stop exercising due to symptoms of breathlessness and fatigue, and it is rare for this to coincide with a plateau in oxygen consumption. ${ }^{34}$ As a result both exercise time and peak $\mathrm{VO}_{2}$ reached depend on motivation of the patient and the extent to which the patient is encouraged by the physician supervising the exercise test.

Other more objective measures have been suggested, in particular the anaerobic threshold. The anaerobic threshold is a point during exercise when the requirements of the exercising tissues are no longer met, and anaerobic metabolism ensues, generating lactate. The lactate is buffered by bicarbonate in the blood, and the threshold is detected as an increase in the rate of carbon dioxide production $\left(\mathrm{VCO}_{2}\right)$ relative to $\mathrm{Vo}_{2}{ }^{5}$ Anaerobic threshold has been shown to correlate with peak $\mathrm{Vo}_{2}{ }^{6}$ and has been shown to be reproducible. ${ }^{7}$ Metra et al were able to identify a discrete lactate threshold in all patients in a study on 34 patients, $^{8}$ and anaerobic threshold has been proposed as an index for monitoring the progress of patients with chronic heart failure. ${ }^{9}$

A second measure proposed is that of the extrapolated $\mathrm{Vo}_{2}$ max described by Buller and Poole-Wilson. ${ }^{10}$ The extrapolated $\mathrm{Vo}_{2}$ max is derived from the same data as the aerobic threshold, but all data points are treated equally. Metabolic gas exchange data are modelled to the equation $\mathrm{Y}=\mathrm{aX}-\mathrm{bX}{ }^{2}$ where $\mathrm{X}$ is carbon dioxide production and $\mathrm{Y}$ oxygen consumption. From this mathematical model, it is possible to obtain a reproducible variable, extrapolated $\mathrm{Vo}_{2} \max \left(\mathrm{a}^{2} / 4 \mathrm{~b}\right)$; this represents the extrapolated $\mathrm{Vo}_{2}$ max had the patient been able to exercise to a theoretical plateau of $\mathrm{Vo}_{2}$.

The relation between ventilation and carbon dioxide production $\left(\mathrm{VE} / \mathrm{VCO}_{2}\right.$ slope) is abnormal in patients with heart failure, so that the slope of this relation, although close to a linear regression equation, as in controls, ${ }^{11}$ is much steeper. The increase in the $\mathrm{VE} / \mathrm{VCO}_{2}$ slope correlates with the decrease in $\mathrm{VO}_{2}$ max. ${ }^{12}$ The $\mathrm{VE} / \mathrm{VCO}_{2}$ slope can thus be used as a further index of severity in chronic heart failure. 
Table 1 Patient characteristics

\begin{tabular}{|c|c|}
\hline Characteristic & Talue \\
\hline $\begin{array}{l}\text { Mean (range) age (yr) } \\
\text { Diagnosis (n) } \\
\text { NYHA } \\
\text { peak Vo }{ }_{2} \\
\text { Diuretic equivalent (mg) }\end{array}$ & 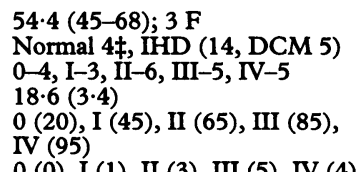 \\
\hline & \\
\hline \multicolumn{2}{|c|}{$\begin{array}{l}\text { NYHA, New York Heart Association classification of symp- } \\
\text { toms in chronic heart failure; IHD, ischaemic heart disease; } \\
\text { DCM, dilated cardiomyopathy. Peak } \mathrm{VO}_{2} \text {, peak oxygen con- } \\
\text { sumption in ml/kg/min. } \text { A Average daily dose of diuretic equiv- } \\
\text { alent to a dose of frusemide by NYHA class. ( } 2 \mathrm{mg} \\
\text { bumetanide is assumed to be equivalent to } 40 \mathrm{mg} \text { frusemide). } \\
\text { ACE, angiotensin converting enzyme. Numbers of patients in } \\
\text { each NYHA category taking an ACE inhibition. fFour sub- } \\
\text { jects aged } 45 \cdot 8(10 \cdot 3) \text { presenting with shortness of breath who } \\
\text { had no cardiopulmonary abnormality on investigation. } \\
\text { Average peak } \mathrm{VO}_{2} \text { in this subset was } 40.5 \mathrm{ml} / \mathrm{kg} / \mathrm{min} \text {. }\end{array}$} \\
\hline
\end{tabular}

The measurements of anaerobic threshold, extrapolated $\mathrm{VO}_{2}$ max, and $\mathrm{VE} / \mathrm{VCO}_{2}$ slope do not in theory depend on reaching $\mathrm{Vo}_{2} \max$, but because of the mathematical techniques, different values could be obtained if only the data from early exercise are used. This study was designed to examine the effects of variations in patients' effort during exercise on the final value for anaerobic threshold, extrapolated $\mathrm{VO}_{2}$ max, and the $\mathrm{VE} / \mathrm{VCO}_{2}$ slope. Specifically, we wished to find whether the values obtained varied with duration of exercise. We also analysed the data up to the point where the respiratory gas exchange ratio reached 1. Exercise beyond this point is often taken to indicate that near maximal exercise tolerance has been reached. ${ }^{1314}$

\section{Patients and methods}

Maximal exercise tests from 23 consecutive patients were analysed. The exercise tests were all carried out on a treadmill with a standard Bruce protocol and an additional stage 0 for the first three minutes exercise at 1 mile hour with a $5 \%$ gradient. Subjects were encouraged to exercise to exhausation. Exercise test results were only analysed if

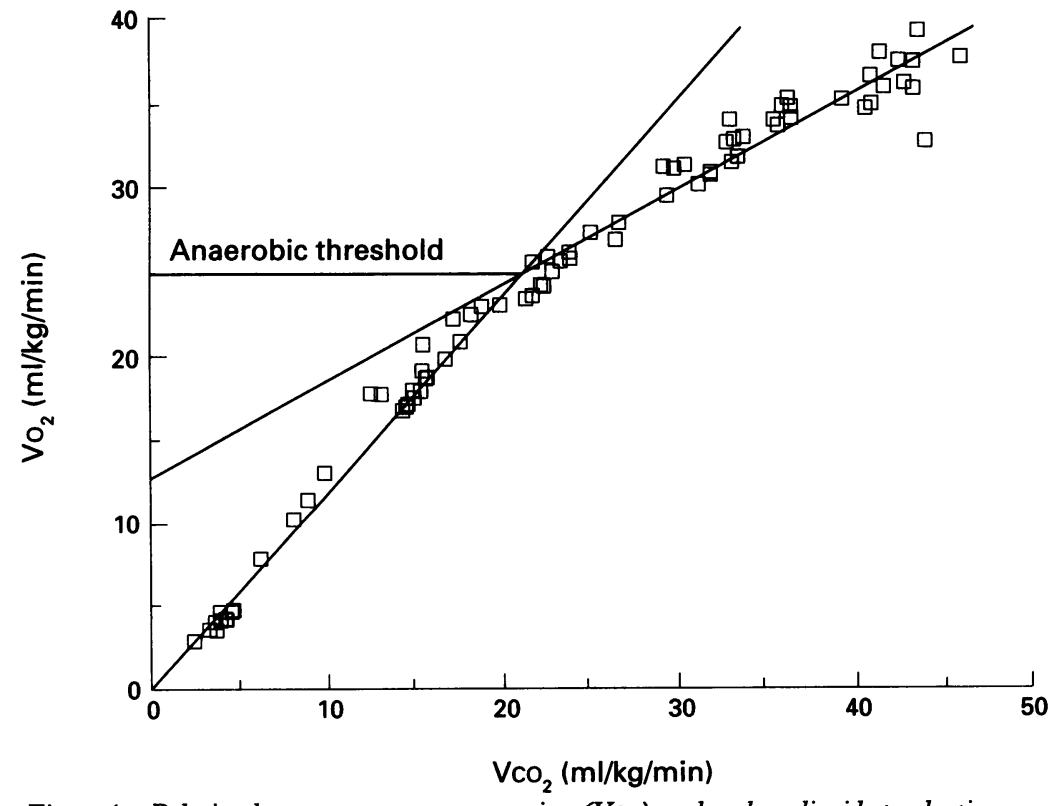

Figure 1 Relation between oxygen consumption $\left(\mathrm{Vo}_{2}\right)$ and carbon dioxide production $\left(\mathrm{VCO}_{2}\right)$ in one patient. The plot shows the derivation of anaerobic threshold. subjects had exercised to a point where the respiratory gas exchange ratio $\left(\mathrm{VCO}_{2} / \mathrm{Vo}_{2}\right)$ had reached at least $1 \cdot 0$, and if the limiting factor to exercise was fatigue or breathlessness. The exercise tests were all conducted for clinical reasons in patients with exercise limitation caused by suspected left ventricular dysfunction. Table 1 shows patient variables. All subjects were non-oedematous. All patients except two were familiar with the exercise protocol, having had at least one previous exercise test with expired gas analysis in the past (average (range) 4.3 months one week to one year) before the current test). A subset of 10 patients undertook two exercise tests a week apart to allow assessment of the reproducibility of the variables.

Subjects expired through a one way valve connected to a mass spectrometer (Innovision, Denmark). Ventilation, $\mathrm{Vo}_{2}$ and $\mathrm{VCO}_{2}$ were calculated on line every 10 seconds by a standard inert gas dilution technique. ${ }^{315}$

The data collected were used to derive values for anaerobic threshold, extrapolated $\mathrm{Vo}_{2}$ max, and $\mathrm{VE} / \mathrm{VCO}_{2}$ slope. Values were recalculated including only those data points for the first $90 \%$ of exercise, and then again including only the first $75 \%$ of exercise. We also calculated the same indices for the data up to the point at which a respiratory gas exchange ratio of 1 was reached; this point is often taken to indicate that exercise is near the maximum.

Anaerobic threshold was calculated by modelling $\mathrm{VCO}_{2}$ as a function of $\mathrm{Vo}_{2}$. Regression lines are computed for the data before and after an inflection on the $\mathrm{VCO}_{2} / \mathrm{Vo}_{2}$ slope, and the intersection of these lines is the anaerobic threshold (fig 1). Extrapolated $\mathrm{Vo}_{2}$ max was derived by fitting a curve to the data plotted as $\mathrm{Vo}_{2}$ as a function of $\mathrm{VCO}_{2}$ (fig 2). ${ }^{10}$ The VE/ $/ \mathrm{VCO}_{2}$ slope was calculated as a linear regression function. In all cases, the regression coefficient was $>0.9$. Both $\mathrm{VE}$ and $\mathrm{VCO}_{2}$ were measured in litres/minute, so the slope has no dimensions. All these indices were calculated by microcomputer to remove any possible contribution of observer bias.

Comparisons were made by paired Student's $t$ test, with corrections for multiple comparisons by Scheffe's procedure. Corrected $p$ values of $>0.05$ were taken to be significant. Results are quoted as means (SEM).

\section{Results}

In the group of 10 patients undertaking two exercise tests, the average peak $\mathrm{Vo}_{2}$ was 16.5 $\mathrm{ml} / \mathrm{kg} / \mathrm{min}(5 \cdot 2)$ for week 1 , and $16.5(5 \cdot 1)$ for week 2. The $\mathrm{VE} / \mathrm{VCO}_{2}$ slope for week 1 was $37.4(11.4)$ and for week $238.0(13.0)$. Anaerobic threshold was 11.8 (3.6) $\mathrm{ml} / \mathrm{kg} / \mathrm{min}$ in week 1 and $12 \cdot 1$ (3.9) in week 2. Extrapolated $\mathrm{Vo}_{2}$ max was $17 \cdot 3(2 \cdot 1)$ $\mathrm{ml} / \mathrm{kg} / \mathrm{min}$ in week 1 and $18.2(2.5)$ in week 2 . Thus in this group of patients, there seemed to be no familiarisation effect with repeated exercise tests. All these patients had previously had exercise tests, however, and 


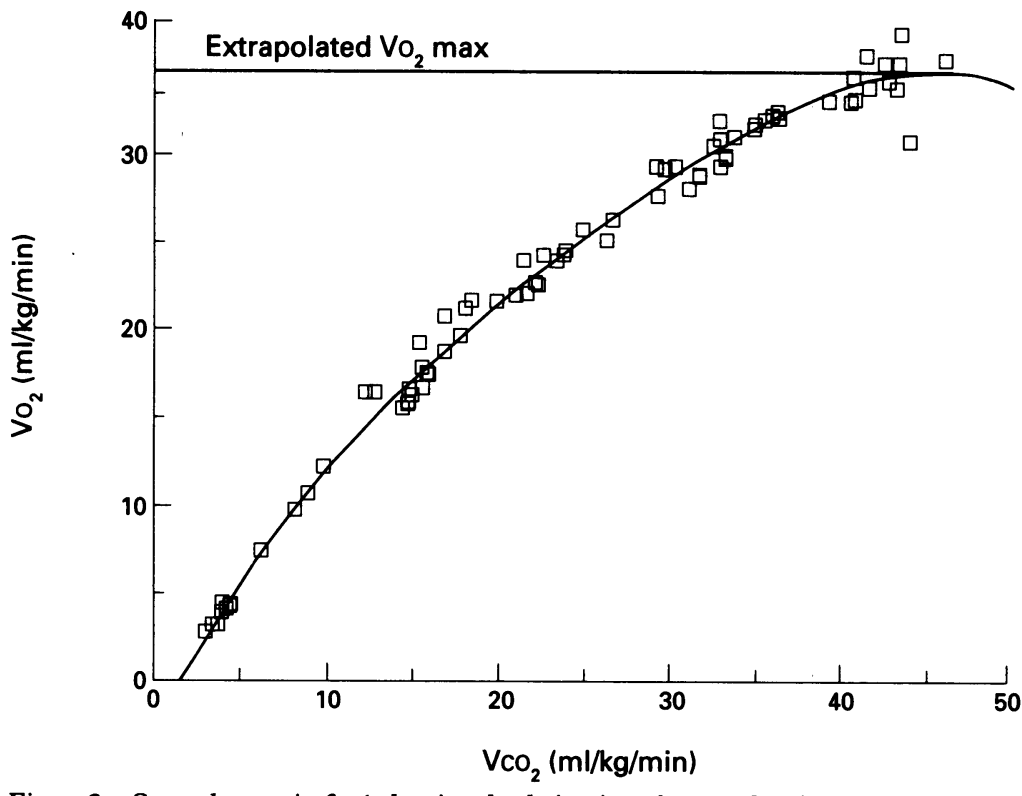

Figure 2 Same data as in fig 1 showing the derivation of extrapolated $\mathrm{VO}_{2}$ max.

may be considered already familiar with the procedure.

Table 2 shows the results for all patients. All patients reached a respiratory gas exchange ratio of over 1.0 at peak exercise. The mean (SEM) respiratory quotient at $90 \%$ of exercise was still greater than 1.0 in all but three patients $(1.07(0.02)$ and at $75 \%$ of exercise it was $0.98(0.02)$.

Anaerobic threshold could not be computed for one subject at $75 \%$ of exercise due to an inadequate number of points, and extrapolated $\mathrm{VO}_{2}$ max could not be computed for two subjects at $90 \%$ and at $75 \%$ of exercise as an exponential curve could not be fitted to the data. The $\mathrm{VE} / \mathrm{VCO}_{2}$ slope was calculated in all instances.

The anaerobic thresholds calculated from data up to $90 \%$ and $75 \%$ of exercise were significantly lower than the values obtained with $100 \%$ of exercise duration. At $90 \%$ the value was $5.3 \%$ lower, and at $75 \%, 13.6 \%$ lower than from the data for the whole of exercise. Extrapolated $\mathrm{Vo}_{2}$, by contrast, was unchanged when computed with the data for $90 \%$ of exercise, but was $12.6 \%$ higher when computed at $75 \%$ of eventual peak exercise.

The $\mathrm{VE} / \mathrm{VCO}_{2}$ slope was also altered when considered at earlier stages of exercise. Although the linear regression coefficient remained greater than 0.9 at all times, the

Table 2 Mean (SEM) results computed from 23 exercise tests with all the exercise data (100\%), data from the first $90 \%$ of exercise, and data from the first $75 \%$ of exercise, and from when each subject first reached a respiratory quotient of 1

\begin{tabular}{|c|c|c|c|c|}
\hline & $\begin{array}{l}\text { Anaerobic } \\
\text { threshold } \\
\text { (ml/kg/min) }\end{array}$ & $\begin{array}{l}\text { EMOC } \\
\text { Extrapolated } \\
\text { VO } \mathrm{O}_{2} \text { max } \\
\text { ( } \mathrm{ml} / \mathrm{kg} / \mathrm{min})\end{array}$ & $\begin{array}{l}\mathrm{VE} / \mathrm{VCO}_{2} \\
\text { slope }\end{array}$ & $\begin{array}{l}\text { Respiratory } \\
\text { quotient }\end{array}$ \\
\hline $100 \%$ & $13 \cdot 2(1 \cdot 0)$ & $25 \cdot 4(2 \cdot 1)$ & $32.3(1.5)$ & $1.15(0.02)$ \\
\hline $\begin{array}{l}90 \% \\
\text { p Value }\end{array}$ & $\begin{array}{l}12.5(1.0) \\
<0.001 v 100 \%\end{array}$ & $\begin{array}{l}25 \cdot 2(1 \cdot 8) \\
\text { NS }\end{array}$ & $\begin{array}{l}30.0(1.5) \\
<0.001 v 100 \%\end{array}$ & $\begin{array}{l}1.07(0.02) \\
<0.001 v 100 \%\end{array}$ \\
\hline $\begin{array}{l}75 \% \\
\text { p Value }\end{array}$ & $\begin{array}{l}11.4(0.7) \\
0.006 \text { v } 90 \%\end{array}$ & $\begin{array}{l}28 \cdot 6(2 \cdot 1) \\
<0.001 v 100 \%\end{array}$ & $\begin{array}{l}28.3(1.4) \\
<0.001 v 90 \%\end{array}$ & $\begin{array}{l}0.98(0.02) \\
<0.001 v 90 \%\end{array}$ \\
\hline $\begin{array}{l}\text { Respiratory } \\
\text { quotient }=1 \\
\text { p Value }\end{array}$ & $\begin{array}{l}11.8(0.9) \\
0.003 v 100 \%\end{array}$ & $\begin{array}{l}28 \cdot 1(1 \cdot 6) \\
\text { NS }\end{array}$ & $\begin{array}{l}27.5(1.4) \\
<0.001 v 100 \%\end{array}$ & - \\
\hline
\end{tabular}

slope was lower at earlier stages of exercise. The slope was $7 \%$ lower when calculated at $90 \%$ of exercise $(p<0.001 v 100 \%)$ and $12.4 \%$ lower when calculated from the data at $75 \%$ of exercise $(\mathrm{p}<0.001 v 90 \%)$.

The data from the experimental runs to the point where a respiratory gas exchange ratio of 1 was reached show that the anaerobic threshold was lower than at peak exercise $(11.8(0.9) \quad v 13.2(1.0) \mathrm{ml} / \mathrm{kg} / \mathrm{min}, \mathrm{p}<$ $0.005)$, and that the $\mathrm{VE} / \mathrm{VCO}_{2}$ slope was lower at $27.5(1.4) v 32.3(1.5)(\mathrm{p}<0.001)$. The extrapolated $\mathrm{Vo}_{2}$ max was not significantly different from the value obtained with $100 \%$ of the exercise data.

\section{Discussion}

In assessing the severity of chronic heart failure, it is important to be able to derive as objective a measure as possible. It is known that exercise tolerance will vary with the environment, subject motivation and experience, and the enthusiasm of the supervisor. Thus a measure that is relatively independent of these factors is to be welcomed. Anaerobic threshold, extrapolated $\mathrm{Vo}_{2}$ max, and the slope of $\mathrm{VE} / \mathrm{VCO}_{2}$ are three such possible measures.

Anaerobic threshold is attractive. It is straightforward for a computer algorithm to identify, and is an appealing concept. It is not, however, easy to identify in all cases ${ }^{16}{ }^{17}$, and often no distinct point of change in ventilation can be identified. Recent studies showing a smooth transition to anaerobic metabolism at different times in different muscle groups make it unlikely that a single anaerobic point could be relied upon, as shown in a study by Yeh et $a l,{ }^{18}$ who found no observable lactate threshold in venous or arterial blood in normal subjects. It is difficult to know if this theoretical concept has any physiological meaning; certainly, ventricular function is not affected by reaching the anaerobic threshold. ${ }^{19}$ Further, the reduction in blood lactate induced by dichloroacetate in a study by Wilson et al resulted in no change in either peak $\mathrm{Vo}_{2}$ or exercise time. ${ }^{20}$

Extrapolated $\mathrm{Vo}_{2}$ max represents a theoretical $\mathrm{VO}_{2}$ max that would have been achieved had the subject been able to continue to exercise until an objective $\mathrm{Vo}_{2}$ max had been reached. It is calculated from the same data as the anaerobic threshold. One attraction is that it is reported to be independent of patient motivation. ${ }^{10}$ The analysis treats all data points equally.

We have found that when calculated from the data obtained during the first $90 \%$ of exercise, the extrapolated $\mathrm{Vo}_{2} \max$ is unchanged from that obtained during the whole exercise period. Anaerobic threshold, however, is significantly lower when measured at $90 \%$ of peak exercise and is lower again when measured at $75 \%$ of the eventual $100 \%$ exercise. This reflects the fact that there is no discrete anaerobic threshold, and that with increasing exercise, the $\mathrm{VCO}_{2}$ moves smoothly further and further from the $\mathrm{Vo}_{2}$; as 
these points are removed from the calculation, the regression line plotted from the data for this part of exercise becomes shallower, and the aerobic threshold falls.

Similar remarks apply to the extrapolated $\mathrm{VCO}_{2}$ max. As $\mathrm{VCO}_{2}$ moves further from $\mathrm{Vo}_{2}$ at peak exercise, a plateau is formed when $\mathrm{Vo}_{2}$ is plotted against $\mathrm{VCO}_{2}$; this is extrapolated $\mathrm{Vo}_{2} \max$. If the further points are removed, the plateau is less pronounced, and it becomes less precise to fit a curve to the data. Thus there is the effect that as duration of exercise falls, aerobic threshold will overestimate the severity of limitation of exercise by returning a lower value, whereas extrapolated $\mathrm{Vo}_{2}$ max will underestimate by returning a higher value.

The increase in the $\mathrm{VE} / \mathrm{VCO}_{2}$ seen in patients with chronic heart failure provides a valuable insight into understanding the mechanisms underlying the breathlessness of chronic heart failure. Although the slope does seem to be well described by a linear regression function, we have previously shown that the $\mathrm{VE} / \mathrm{NCO}_{2}$ varies from a linear function, and that the degree to which the $\mathrm{VE} / \mathrm{VCO}_{2}$ ratio rises at the end of exercise is a function of the severity of heart failure. ${ }^{21}$ The eventual $\mathrm{VE} / \mathrm{VCO}_{2}$ slope is not well predicted by results from early in exercise. ${ }^{22} 23$ The data presented here confirm that the $\mathrm{VE} / \mathrm{VCO}_{2}$ varies throughout exercise, and is lower earlier in exercise. Thus a poorly motivated subject will have a lower $\mathrm{VE} / \mathrm{VCO}_{2}$ slope, and the degree of impairment of exercise present may be underestimated.

To reach a respiratory gas exchange ratio of 1 is often taken to mean that the exercise performed is near maximal. The data presented here, however, show that at this clinical end point, only extrapolated $\mathrm{Vo}_{2}$ max is a reliable estimate of eventual exercise tolerance. Anaerobic threshold is lower and the $\mathrm{VE} / \mathrm{VCO}_{2}$ slope higher at this point, as might be expected from the findings from $90 \%$ and $75 \%$ of eventual exercise time.

In assessing the severity of chronic heart failure, a range of variables has to be borne in mind. In this study we have shown that extrapolated $\mathrm{Vo}_{2}$ max is a better estimate of exercise tolerance than anaerobic threshold, and if an exercise test has progressed to a point where the respiratory gas exchange ratio is greater than $1 \cdot 0$, then the calculated value for extrapolated $\mathrm{Vo}_{2}$ max is likely to be representative of that subject's exercise capacity. Anaerobic threshold is less reliable; as duration of exercise falls, so does the anaerobic threshold. The $\mathrm{VE} / \mathrm{VCO}_{2}$ slope as an index of severity of chronic heart failure is also importantly affected by patient motivation. Anaerobic threshold tends to overestimate and $\mathrm{VE} / \mathrm{VCO}_{2}$ slope to underestimate the severity of limitation of exercise. Extrapolated $\mathrm{VO}_{2}$ is a better indicator for monitoring patients with chronic heart failure, but the patient should be encouraged to exercise beyond a point where the respiratory gas exchange ratio is 1 .

In this study we have tried specifically to assess the possible effects of patient motivation on possible indices of severity of chronic heart failure during an exercise test. We have not assessed the stability of extrapolated $\mathrm{Vo}_{2}$ max as an exercise end point over time, and it will be important in the future to determine whether changes in extrapolated $\mathrm{Vo}_{2}$ max and $\mathrm{VE} / \mathrm{VCO}_{2}$ follow treatment of chronic heart failure in parallel with increases in peak $\mathrm{VO}_{2}$ and to determine the effect of different exercise protocols, known to affect the measured peak $\mathrm{Vo}_{2}$, on extrapolated $\mathrm{Vo}_{2} \max$ and $\mathrm{VE} / \mathrm{VCO}_{2}$.

This work was supported by the British Heart Foundation, the Robert Luff Foundation, and the Viscount Royston Trust.

1 Mitchell JH, Sproole BJ, Chapman CB. The physiological meaning of the maximal $\mathrm{O}_{2}$ intake test. $\mathcal{f}$ Clin Invest 1958;37:538-47.

2 Weber KT, Wilson JR, Janicki J, Likoff MJ. Exercise testing in the evaluation of the patient with chronic cardiac failure. Am Rev Respir Dis 1984;129:(suppl):S60-2.

3 Lipkin DP, Perrins J, Poole-Wilson PA. Respiratory gas exchange in the assessment of patients with impaired exchange in the assessment of patients with
ventricular function. Br Heart $\mathcal{f} 1985 ; 54: 321-8$.

4 Francis GS. Clinical aspects of heart failure. Current Opinion in Cardiology 1986;1:347-53.

5 Wasserman $K$. Determinants and detection of anaerobic threshold and consequences of exercise above it. Circulation 1987;76(suppl VI:VI29-39.

6 Hoh H, Taniguchi K, Koike A, Doi M. Evaluation of severity of heart failure using ventilatory gas analysis. Circulation 1990;81 (supp1 2): П131-П137.

7 Simonton CA, Higginbotham MB, Cobb FR. The ventilatory threshold: quantitative analysis of reproducibility and relation to arterial lactate concentration in normal subjects and in patients with chronic congestive heart failure. Am ₹ Cardiol 1988;62:100-7.

8 Metra M, Raddino R, Dei Cas L, Visioli O. Assessment of peak oxygen consumption, lactate and ventilatory thresholds and correlation with resting and exercise haemodynamic data in chronic congestive heart failure. Am ₹ Cardiol 1990;65:1127-33.

9 Sullivan MJ, Higginbotham MB, Cobb FR. Exercise training in patients with chronic heart failure delays ventilatory anaerobic threshold and improves submaximal exercise performance. Circulation 1989;79:324-9.

10 Buller N, Poole-Wilson P. Extrapolated maximal oxygen consumption: a new method for the objective analysis of respiratory gas exchange during exercise. Br Heart $\mathcal{f}$ 1988;59:212-7.

11 Whipp BJ. Ventilatory control during exercise in humans. Ann Rev Physiol 1983;45:393-413.

12 Buller NP, Poole-Wilson PA. Mechanism of the increased ventilatory response to exercise in patients with chronic ventilatory response to exercise in patien

13 Sullivan MJ, Higginbotham MB, Cobb FR. Increased exercise ventilation in patients with chronic heart failure: intact ventilatory control despite hemodynamic and pulmonary abnormalities. Circulation 1988;77:552-9.

14 Franciosa JA, Baker BJ, Seth L. Pulmonary versus systemic hemodynamics in determining exercise capacity of temic hemodynamics in determining exercise capacity of 1985;110:807-13.

15 Davies N, Denison DM. Measurement of metabolic gas exchange and minute volume by mass spectrometry alone. Respir Physiol 1979;36:261-7.

16 Lipkin DP, Perrins J, Poole-Wilson PA. Respiratory gas exchange in the assessment of patients with impaired ventricular function. Br Heart $\mathcal{F}$ 1985;54:321-8.

17 Cowley AJ, Fullwood L, Stainer K, Hampton JR. Exercise tolerance in patients with heart failure-how should it be measured? Eur Heart $\mathcal{F}$ 1990;12:50-4.

18 Yeh MP, Gardner MR, Adams TD, Yanowitz FG, Crapo RO. "Anaerobic threshold": problems of determination and validation. $\mathcal{A}$ Appl Physiol 1983;55:1178-86.

19 Rodrigues EA, Maddahi J, Brown H, Panteleo N, Freeman $M$, Koerner $S$, Waxman A, Berman DS. Freeman $M$, Koerner $S$, Waxrin Responses of left and right to aerobic and anaerobic phases of upright and supine exercise

20 Wilson JR, Mancini DM, Ferraro N, Egler J. Effect of dichloroacetate on the exercise performance of patients dichloroacetate on the exercise performance of patients

21 Clark AL, Poole-Wilson PA, Coats AJS. The relationship between ventilation and carbon dioxide production in patients with chronic heart failure. $7 \mathrm{Am}$ Coll Cardio 1992;20:1326-32.

22 Metra M, Dei Cas L, Panina G, Visioli O. Exercise hyperventilation chronic congestive heart failure and its relation to functional capacity and hemodynamics. $A m \mathcal{F}$ Cardiol 1992;70:622-8.

23 Clark AL, Coats AJS. Exercise hyperventilation chronic congestive heart failure and its relation to functional capacity and hemodynamics. Am $\mathcal{f}$ Cardiol 1993;71 capacity 